\title{
NOVOS TEMPOS, NOVAS PRÁTICAS... repensando metodologia e avaliação no Ensino Superior - Relato de Pesquisa
}

\section{New times, new practices... rethinking methodology and evaluation in higher Education - Research report}

\author{
Valéria Ramos Leitão* \\ Lúcia Raquel Miranda Passerino** \\ Lílian Anna Wachowicz**
}

\section{Resumo}

Este artigo apresenta considerações sobre a ação docente na PUCPR em relação à implantação dos novos projetos pedagógicos dos cursos de graduação. A partir dos pressupostos educacionais - a visão do todo e a produção do conhecimento - é encaminhada uma reorganização da prática pedagógica no ensino superior. A prática docente, proposta pelos programas de aprendizagem que compõem o Projeto Pedagó gico, resulta da articulação entre competências, meto dologia, temas de estudo e avaliação, em decorrência da concepção de educação e da natureza da área do conhecimento, mas sempre a partir do projeto vivido.

Palavras-chave: Ação docente, Metodologia e avaliação, Projeto pedagógico, Evolução.

* Mestre em Educação, Professora da Área de Educação na PUCPR e membro do Núcleo de Avaliação, Apoio e Desenvolvimento Docente da PUCPR.

E-mail: vleitão@rla01.pucpr.br

** Mestre em Educação, Professora da Área de Educação na PUCPR e membro do Núcleo de Avaliação, Apoio e Desenvolvimento Docente da PUCPR.

E-mail: passerin@rla01.pucpr.br

*** Doutora em Educação e Professora da Área de Educação, na PUCPR.

Pontifícia Universidade Católica do Paraná - Mestrado em Educação

Rua Imaculada Conceição, 1155, Prado Velho, Curitiba - PR, CEP 80215-901.

E-mail: lil@rla01.pucpr.br 


\section{Abstract}

This article presents considerations on the teaching action at PUCPR in relation to the implantation of the new pedagogical projects of the undergraduate courses. From the educational assumptions - the whole vision and the knowledge production - a reorganization of the pedagogical practice in highereducation is directed. The teadring proposed by the leaming programs, that compose the Pedagogical Project, results from the integration between competencies, methodology, study themes and evaluation because of the educational conception and the nature of the knowledge area, but always form the lived project.

Keywords: Teaching action, Methodology, Educational project, Evaluation.

\section{Introdução}

Os novos paradigmas educacionais foram criados a partir das mudanças na prática docente em todos os níveis de ensino, mudanças essas que foram tornando-se necessárias pela força das mudanças na sociedade. Experiências realizadas em universidades podem servir para reflexões em diferentes instituições de ensino fundamental e médio, relatando os caminhos a serem vivenciados, com a intencionalidade de compartilhar a reflexão da prática, para compreender suas possibilidades de transformação.

Este trabalho centra sua abordagem no estudo de mudanças na prática docente que emergem do processo de renovação pedagógica que se instalou na Pontifícia Universidade Católica do Paraná - PUCPR - em relação aos novos projetos pedagógicos dos cursos de graduação.

Um dos aspectos desta mudança é a proposta metodológica e avaliativa a ser vivenciada em sala de aula, que somente revela seu pleno sentido quando tem sua reflexão fundamentada no contexto de uma política institucional coerente com uma concepção de educação explicitada e analisada pelas pessoas envolvidas, protagonistas da mudança.

Nesta ótica, o que é necessário que o professor considere no aspecto metodológico e de avaliação, ao se dispor para uma ação pedagógica transformadora, em sua sala de aula?

\section{Desafio da Mudança e a PUCPR}

O momento atual da educação brasileira, especialmente no que se refere ao ensino superior, é de profundas alterações em face das exigências sociais, algumas delas contempladas na nova legislação, explicitada, porém ainda não suficientemente tratada em sua proposta, na Lei Federal n.․ 9394/ 96.

As mudanças na organização econômica, política e cultural estão a 
exigir um profissional diferenciado, com um perfil que possibilite agir em um momento histórico em que a característica é a incerteza, e que possa atuar com criticidade, autonomia e espírito de investigação, no dizer de Behrens (1999).

As transformações aceleradas advindas de uma sociedade, cuja moeda principal vem sendo o conhecimento, desafiam as universidades a buscarem novas alternativas nas suas propostas de graduação, que contemplem uma nova concepção de mundo, de sociedade e de homem.

As tendências do mundo globalizado demandam um repensar sobre a estrutura curricular que os cursos oferecem aos estudantes que freqüentam as universidades e também novas maneiras de ensinar e de aprender. 0 repensar dos cursos é, pois, uma imposição, sem o que a universidade deixa de cumprir seu papel fundamental: a formação humana de cidadãos para uma atuação efetiva e uma consciência crítica no mercado de trabalho e na sociedade. Trata-se, portanto, de uma tarefa da mais alta importância, que deverá ser efetivada com 0 envolvimento de todo o corpo docente e discente de um curso.

Neste sentido, desde 1998 a PUCPR vem desenvolvendo um trabalho relacionado aos projetos pedagógicos dos cursos de graduação, numa concepção inovadora de educação. No seu Plano Estratégico, a instituição indica suas opções, em termos de "um diferencial competitivo", explicitando-se a ênfase na valorização da formação humana.

- qualidade do ensino,

- qualidade do corpo docente,

- qualidade das relações humanas,

- qualidade do seu produto final: o egresso.

O referido Plano estabelece ações a serem desenvolvidas em cinco grandes áreas, dentre as quais se destaca a "qualidade e diferenciação das ações de ensino". (Quais áreas?).

Também o Documento sobre as Diretrizes Internas para Implantação dos Projetos Pedagógicos da PUCPR refere-se às ações de ensino propondo a criação de "condições importantes para orientar o trabalho de ensino de cada um de seus professores em cada um dos cursos..." (1998, p. 18).

O desafio de mudar a proposta de educação superior na Instituição aparece como um processo de reconstrução. Passa pela necessidade de uma organização criativa nos projetos pedagógicos dos cursos, bem como da revisão da prática pedagógica do professor, especialmente nos aspectos de metodologia e avaliação, sem perder de vista as questões político-sociais, face às contradições e à complexidade da nossa realidade. 


\section{Concepção de Educação}

A concepção de educação, face aos novos marcos teóricos da contemporaneidade, volta-se para o desenvolvimento humano numa dimensão ética e cultural, visando a capacidade de "aprender a aprender" com autonomia, para o repensar da prática social.

O documento da UNESCO, ao propor os fundamentos da educação para o século XXI, estabelece quatro pilares: aprender a conhecer, aprender a fazer, aprender a ser e aprender a conviver.

É uma concepção que pretende formar o homem capaz de recriar-se constantemente, tendo em vista as transformações da sociedade e considerando os saberes acumulados pela experiência humana.

Assim é que a visão do todo e a produção do conhecimento se inserem como pressupostos básicos para o processo de aprendizagem. Com estes, outros emergem de modo a nortear a ação pedagógica em sala de aula: autonomia, ensino com pesquisa, interdisciplinaridade, contextualização, problematização, aluno ativo, parceria, participação, "negociação" do contrato pedagógico, tecnologias educacionais, aprendizagem significativa, ética, cidadania.

Na concretização deste processo é importante considerar a epistemologia própria dos diferentes campos do conhecimento, que são construídos a partir dos princípios que os caracterizam, enquanto formam uma estrutura de relações teóricas.

O professor especialista, junto aos demais professores de outras áreas, é capaz de planejar a ação pedagógica estabelecendo as relações necessárias entre a concepção de educação, o projeto pedagógico e os programas de aprendizagem vivenciados em sala de aula. É necessário contextualizar os conhecimentos em questão, bem como ter presente a problematização gerada e geradora destes conhecimentos, para nortear a ação docente.

\section{Ação Pedagógica}

No desenvolvimento de sua ação docente, os professores mobilizam um conjunto de saberes para a "gestão da classe e gestão da matéria" conforme afirmam Tardif e Raymond (2002, p. 209).

Entretanto, para alguns docentes do ensino superior, o referencial para atuação em sala de aula são os modelos de seus próprios professores, 0 que algumas vezes leva a uma atuação baseada na sua própria experiência como aluno. Esse é apenas um dos movimentos históricos que demonstram a prioridade epistemológica da prática. $\mathrm{O}$ que se propõe é a reflexão, exercida no coletivo instituído, com a prática social vivida, neste caso a prática profissional do educador na Universidade. 
São vários conhecimentos e competências necessários ao pensar o fazer pedagógico, os quais superam o domínio do conteúdo, por mais profundo que possa ser. Abrangem imensa gama de questões que envolvem desde as relações intra e interpessoais, as políticas educacionais vigentes, até o uso apropriado de material didático e das novas tecnologias. Constituem um conjunto de saberes pedagógicos que subsidiam o ato de ensinar.

Alguns autores se têm debruçado sobre os diferentes aspectos que compõem estes saberes dos professores.

Tardif e Raymond (2002), por exemplo, apontam:

- Saberes pessoais dos professores.

- Saberes provenientes da formação escolar anterior.

- Saberes provenientes da formação profissional para o magistério.

- Saberes provenientes dos programas e livros didáticos usados no trabalho.

- Saberes de sua própria experiência na profissão, na sala de aula e na escola.

Também na ótica do exercício profissional, Pimenta apresenta como saberes da docência (1996):

- A experiência.

- O conhecimento.

- Os saberes pedagógicos.

Por outro lado, Saviani (1996) enfatiza os saberes que integram a formação do educador, considerando que os saberes decorrentes da experiência estão contidos em todos os demais saberes:

- Saber atitudinal.

- Saber crítico - contextual.

- Saberes específicos.

- Saber pedagógico.

- Saber didático - curricular.

Fica claro que ao atuar no magistério superior torna-se necessário que o professor aprofunde competências de gestão do processo pedagógico, de motivação e de liderança, bem como outras que se referem aos saberes da docência, tais como questões de metodologia e avaliação, concorrendo para 0 estabelecimento de uma identidade do professor da PUCPR.

Em cada instituição de ensino, forma-se a identidade do professor na relação do cotidiano com a História. Assim como na Física, em Educação o todo é mais do que a soma das partes: a cultura institucional é criada pelas relações dos sujeitos da educação escolar no seu cotidiano, com as determinações do tempo e do espaço instituídos, os quais se tornam os instituintes daquela cultura. 
Perrenoud (2000) propõe o desenvolvimento de competências de um professor profissional, entre as quais cabe ressaltar: organizar e dirigir situações de aprendizagem, administrar a progressão das aprendizagens, envolver os alunos em suas aprendizagens e em seu trabalho.

Muito antes de serem divulgadas as coordenadas da metodologia da reflexão no coletivo das instituições educacionais e da consideração da prática pedagógica dos professores no cotidiano social escolar, uma experiência metodológica realizada no Paraná pode demonstrar não somente essa proposta teórica, mas também nossa afirmativa de que a teoria se faz pela prática, assim como a História se faz pelo cotidiano, não tomado em si mesmo, mas pelas relações de espaço e tempo. Martins (1985), em sua dissertação de Mestrado defendida na Universidade Federal de Minas Gerais, apresenta um trabalho ligado a uma experiência intensamente vivida e pensada... A investigação realizou-se com um grupo de oitenta professores de Primeiro Grau, atuantes na rede estadual de ensino, no município de Arapongas, norte do Paraná. "A escolha dos oitenta professores ocorreu aleatoriamente seguindo a ordem de inscrição para participação do encontro 'A busca de alternativas para a reformulação da prática pedagógica' realizado sob os auspícios da Secretaria de Estado da Educação do Paraná (SEED), em convênio com a Faculdade de Filosofia, Ciências e Letras de Arapongas, minha Instituição de origem" (MARTINS, 2002, p. 9-17).

A metodologia criada nesse trabalho anunciava e colocava em ação o que hoje se chama a epistemologia da prática e a formação do professor reflexivo e crítico. Dizia o editor, desde a primeira edição do livro:

Pura Lúcia Oliver Martins apresenta um estudo original e polêmico sobre a Didática, a partir dos problemas concretos que o professor encontra em seu dia a dia.. Partindo dos desencontros entre a teoria e a prática, a autora procura um caminho metodológico que questione as teorias e estimule a reflexão com a prática. $\mathrm{O}$ que se pretende é uma nova Didática (...) fugindo do pressuposto de que a teoria seja a guia da prática, para descobrir a lógica da classe trabalhadora, cujo princípio é: o saber se dá no fazer.

Na seqüência dos acontecimentos da História da Pedagogia da Ação, as análises do processo de transformação do trabalho docente foram algumas vezes apresentando-se descontextualizadas quanto ao princípio educativo do trabalho e da consideração do professor como trabalhador. Esse equívoco, embora tenha favorecido certo sucesso de alguns autores ao apresentarem propostas mais agradáveis, porque aproximadas e misturadas às propostas neoliberais que tiveram hegemonia nos anos 90, na prática revelou suas contradições. A negativa de se tomar o trabalho docente pela sua raiz e a 
tentativa de se prosseguir tratando a educação escolar como uma mercadoria, levaram as instituições de ensino ao impasse do investimento na força de trabalho, ou seja, nos professores e alunos, sem que pudessem compreender que os investimentos em capital constante, tais como construções e equipamentos, são importantes apenas na medida em que cumprem os objetivos do trabalho pedagógico. A própria evolução do mercado trouxe às instituições de ensino, mais do que a compreensão da concepção da relação capital - trabalho, as exigências do investimento na qualidade das relações na formação humana.

O Projeto Pedagógico dos Cursos de Graduação estabelece novos princípios para a educação na PUCPR propondo que o professor reveja seu próprio trabalho, desestabilizando a rotinização instalada e voltando-se para 0 estudo dos vários fenômenos importantes que compõem a relação professoraluno-universidade, os quais são explicitados na proposta curricular.

A opção pela designação de equipes responsáveis pela articulação dos diferentes elementos da organização curricular pressupõe a participação de toda a comunidade acadêmica. É o envolvimento do professor, dos estudantes e da gestão da instituição, nas suas relações, que vai garantir o sucesso da implantação de uma proposta curricular.

Pode-se afirmar que o próprio processo de reformulação curricular é um elemento de envolvimento e preparação docente, com um acentuado caráter participativo. É no contexto da discussão, da reflexão, do questionamento, que vão se definindo e consolidando uma cultura de envolvimento e corresponsabilidade.

O que se investe em tempo e esforço coletivo no redesenhamento do curso é amplamente compensado no momento de vivência da nova proposta curricular. Quanto mais claras estiverem para o docente as mudanças das quais ele estiver participando, mais seguro e confiante ele vai sentir-se, pois é a consciência de si e de seu próprio trabalho que leva o professor a participar ativamente do sucesso da nova proposta nos espaços de aula.

Tal qual nas demais instituições sociais, a ênfase se dá no saber trabalhar em equipe e realizar projetos em grupo. Esta é uma das tônicas dos novos tempos, sendo, portanto, uma necessidade a ser assegurada na universidade.

Um currículo inovador implica entre outros aspectos na opção por uma metodologia que tenha como foco a aprendizagem, isto é, conceber projetos pedagógicos que privilegiem atividades organizadas a partir dos pressupostos de um novo paradigma, no qual a ênfase é o aprender do aluno.

A proposta da PUCPR envolve uma mudança significativa de foco ao deslocar o eixo de atenção do ensino para a aprendizagem, ao mesmo tempo em que concentra o trabalho pedagógico no desenvolvimento de competências dos alunos em vez do simples acúmulo de conteúdos. A construção do conhecimento por parte do estudante na compreensão dos fenômenos com- 
plexos é a proposta que fundamenta os programas de aprendizagem que compõem a estrutura curricular do projeto pedagógico de cada curso.

Os programas de aprendizagem, em substituição às antigas disciplinas, não correspondem apenas a uma mudança de denominação, mas representam uma perspectiva diferente do trabalho docente e discente, resgatando a integração do conhecimento na visão do todo.

Nesse enfoque a sala de aula se constitui num espaço dinâmico de construção do conhecimento. Aqui é colocada a questão fundamental desta discussão: "Como elaborar uma proposta de ação pedagógica, cuja metodologia e avaliação estejam voltadas para a sala de aula, com ênfase na aprendizagem do aluno?'

Para que se construa uma prática pedagógica inovadora, à luz de uma nova concepção de educação, é importante uma reflexão sobre diferentes aspectos do processo pedagógico, especialmente os procedimentos metodológicos e a avaliação processual. Conforme Anastasiou, "na aula ensina-se o quê e o como pensar, portanto, para além do conteúdo..." (1998, p. 173).

Os pressupostos fundamentais da concepção de educação, a visão do todo e a produção do conhecimento permitem ir além da simples aquisição de informações, da fragmentação do conhecimento, de um processo centrado no conteúdo e no ensino do professor, que caracterizaram o desenvolvimento do currículo em disciplinas. A proposta é desenvolver um trabalho com programas de aprendizagem que oportunizam a integração do conhecimento, conferindo um novo sentido à sala de aula.

Os programas de aprendizagem de um curso de graduação podem originar-se de diferentes formas, dentre as quais apontamos:

- Da integração de duas ou mais disciplinas afins, cujos temas comuns formam um eixo integrador.

- Das linhas de pesquisa do curso voltados, principalmente, à produção científica de alunos e professores.

- De projetos relacionados às linhas de pesquisa ou grupos de estudos.

- Das orientações contidas nas Diretrizes Curriculares dos diferentes cursos de graduação, entre outros.

Os programas de aprendizagem, criados a partir de uma nova concepção de educação, atendem à natureza da área do conhecimento e do curso a que pertencem, e a relação existente entre um conjunto de competências, temas de estudo, procedimentos metodológicos e avaliação processual. Esta visão integrada é fundamental para a compreensão do novo enfoque metodológico e avaliativo. 


\section{Competências}

Ao aluno, futuro profissional das diferentes áreas de conhecimento, são exigidas determinadas competências que superam a simples aquisição de informações e privilegiam sua formação no sentido de desenvolver modos de pensar e agir, compatíveis com o contexto em que vai atuar. É preciso pensar, decidir, considerar, multiplicar e avaliar alternativas diante de situações diversas; ser crítico, político, ético.

Competência refere-se a um conjunto de saberes que colocam em sinergia processos cognitivos conjugados e organizados, permitindo a contextualização, identificação e concretização de uma ação em diferentes situações. Não se refere apenas a ações específicas profissionais, mas ao aprender a conhecer, aprender a fazer, aprender a conviver e aprender a ser. As competências, no sentido do processo pedagógico, são aquisições, aprendizagens construídas, um dispositivo de transposição didática para integrar a cultura de uma profissão nos programas de aprendizagem.

A mudança de eixo do ensino pelos conteúdos para a aprendizagem centrada em competências está ainda em estágio inicial, pois, como enfatiza Perrenoud, "o reconhecimento da própria pertinência da noção de competência continua a ser um desafio nas ciências cognitivas, assim como na didática" (1999, p. 8).

Esse desafio, ousamos afirmar, talvez tenha sua raiz na descontextualização de que já falamos, do trabalho docente ainda considerado em si mesmo, distante de seu significado político.

No contexto do programa de aprendizagem, competência remete ao desafio do sujeito para mobilizar os processos cognitivos no contexto de situações-problemas pertinentes ao curso a que pertence. Mobilizar recursos refere-se à articulação de todas as informações obtidas ao longo de suas aprendizagens naquele programa, de forma integrada com outros programas. Nesta articulação, identificamos, selecionamos, comparamos, avaliamos, estabelecemos relações, levantamos hipóteses, tomamos decisões. São os processos cognitivos desencadeados para a construção do conhecimento de forma integrada e contextualizada.

As informações pertinentes ao programa de aprendizagem traduzemse em temas de estudos, assuntos significativos, antigos conteúdos ou matéria, que devem ser selecionados a partir das competências a serem desenvolvidas.

A percepção desta relação é fundamental para que o professor articule os diferentes aspectos do processo pedagógico. 


\section{Temas de Estudo}

Os temas de estudos são definidos como uma seqüência dos assuntos a serem estudados, enfocados em seus diferentes aspectos: histórico, técnico, econômico, entre outros, de modo a permitir uma visão integrada que será aprofundada em seus múltiplos desdobramentos.

Os desdobramentos convertem-se em itens e subitens do assunto em questão, em dosagem adequada ao tempo e ao nível esperado de aprendizagem dos alunos, priorizando os assuntos que realmente são significativos.

Cabe ressaltar que nesta nova concepção os temas de estudo revestem-se de maior importância porque superam a mera aquisição de informações para compor uma rede de conhecimentos a serem mobilizados.

É no momento de planejar que o professor estabelece os temas que serão objeto de pesquisa e discussão, tendo como referência o conjunto de competências do programa de aprendizagem.

A articulação de projetos entre os professores de diferentes programas de aprendizagem oportuniza uma visão integrada do conhecimento por meio de tarefas que favoreçam mecanismos de motivação dos estudantes, propiciando esquemas que mobilizem diferentes conhecimentos.

A síntese dos temas que os alunos deverão estudar e que se relacionam com as competências a serem desenvolvidas constituem a ementa do programa de aprendizagem.

\section{Procedimentos Metodológicos}

Esse item refere-se ao encaminhamento a ser dado ao processo educativo, ao "como fazer", à prática educativa, isto é, às condições que a instituição proporciona ao professor e aos estudantes para o desenvolvimento das competências selecionadas bem como as atividades de aprendizagem que devem ser realizadas pelos alunos. Quanto a este encaminhamento, "o que importa é a capacidade do professor para traduzir os conteúdos da aprendizagem em procedimentos de aprendizagem, isto é, em uma seqüência de operações mentais que ele procura compreender e instituir na sala de aula" (MEIRIEU, 1998, p. 117).

Para que se promova uma prática inovadora voltada para a construção do conhecimento e para a visão do todo, é importante que o professor esteja consciente de que mudanças não são "óbvias" nem espontâneas, mas criadas a partir das condições materiais e culturais trabalhadas pela instituição. Trata-se da coerência entre uma concepção, sua metodologia e os instrumentos reais criados para sua efetivação. Nas relações da prática social, os instrumentos, a metodologia e a concepção se apresentam poderosos para a mu- 
dança, na proporção de sua coerência.

A criatividade e a inovação só ocorrem no exercício da liberdade e da disponibilidade em procurar, estudar e selecionar atividades adequadas para o processo de desenvolvimento das competências, como também prever conseqüências e possibilidades de avanços, que concorram para as reelaborações necessárias da prática docente e discente.

As competências envolvendo processos cognitivos em sinergia, a serem desenvolvidas por meio de "atividades cognitivas superiores, seriam as metas a atingir no processo de ensino e aprendizagem" (WACHOWICZ, 2000 p. 100).

Para tanto é necessário propiciar uma aprendizagem significativa a partir de atividades que envolvem resolução de situações-problema, observação da realidade, troca de experiências, exercícios, leituras e produção própria. O aluno ativo, a contextualização, a elaboração pessoal e coletiva são pressupostos, entre outros, que privilegiam uma proposta metodológica coerente com a concepção de educação.

Neste processo de construção do conhecimento, outras atividades de aprendizagem podem ser utilizadas tais como a problematização, os seminários, 0 estudo de textos, as discussões em grupos, os exercícios teónicos e práticos, as simulações e demonstrações, as aulas expositivas dialogadas, as visitas técnicas e as dramatizações.

Outras situações envolvendo estágios, visitas, excursões, projetos são particularmente importantes por permitirem a ressignificação do conhecimento à luz do contexto profissional. Não por acaso, os cursos que já trabalhavam com a metodologia da Pedagogia da Ação são os que melhor compreenderam a proposta do Projeto Pedagógico da PUCPR: numa avaliação preliminar, que será objeto de outra publicação, revela-se por exemplo o Curso de Arquitetura como trazendo inovações significativas, avançando na metodologia do ensino por projetos, sendo esta histonicamente a metodologia hegemônica no Curso. Antes da implantação do Projeto Pedagógico implantado na PUCPR em 2000, os professores utilizavam a simulação do planejamento urbano de um município do interior do Paraná. Hoje, utilizam o planejamento urbano real de um município, em convênio instituído pela PUCPR e a Prefeitura Municipal. O convênio, como instrumento metodológico, é bem diferente da simulação e cumpre efetivamente a concepção de ensino e aprendizagem do Projeto, mas somente foi possível na evolução histónica instituinte da Pedagogia da Ação, no Curso de Arquitetura, entre outros exemplos já registrados.

Assim sendo, as atividades de aprendizagem ocomidas durante a aula revestem-se de grande importância, porque é neste momento que alunos e professores trabalham a partir das possibilidades da superação de um modelo de ensino historicamente fragmentado em prol de um processo de recriação da prá- 
tica pedagógica, voltada para a construção do conhecimento.

Importante destacar o papel do equipamento didático como recurso que favorece a aprendizagem do aluno. O professor poderá dispor do material didático existente na instituição para enriquecer seu trabalho, tomando as aulas mais vivas e criativas. Os laboratónios de informática e as bibliotecas com seus múltiplos recursos contribuem significativamente para este processo, sendo esse por sua vez um bom exemplo do lugar social que pode ter o investimento em capital constante.

Masetto ressalta que a "mídia eletrônica pode colaborar significativamente para tornar o processo e a aprendizagem mais eficientes e mais eficazes, mais motivadores e mais envolventes" (2001, p. 99), pois facilitam a intercomunicação e a pesquisa.

\section{Avaliação Formativa}

Partindo da concepção de educação, considerando a natureza da área do conhecimento, as competências e os procedimentos metodológicos, 0 processo de avaliação vai assumindo um caráter formativo, de verificação do nível do desenvolvimento das competências.

A avaliação formativa comunica ao professor e ao aluno o processo de aprendizagem, no sentido de avançar, replanejar, redirecionar e retomar aspectos significativos para o processo educativo. Neste sentido, segundo Hadji são: "as correções a serem feitas com o objetivo de melhorar o desempenho do aluno, e que concernem portanto tanto à ação de ensino do professor quanto à atividade de aprendizagem do aluno, são escolhidas em função da análise da situação, tornada possível pela avaliação formativa" (2001, p. 21).

O processo de avaliação formativa caracteriza-se pelas suas dimensões indissociáveis:

- prognóstica: na medida em que identifica os porquês dos avanços e limitações no processo de aprendizagem e o que deve ser feito de modo a superar as dificuldades;

- contínua: refere-se aos diferentes momentos de avaliação durante o processo de aprendizagem;

- cumulativa: refere-se à verificação das aquisições de competências em determinados períodos, na medida em que o aluno agrega conceitos promovendo sínteses cognitivas, aprofundando seus estudos, melhorando seus trabalhos. Nossos últimos estudos trazem a avaliação formativa na sua relação com a metacognição, podendo agora falarmos em metavaliação: ao tomar conscientes suas estratégias pessoais de aprendizagem, os estudantes auto-avaliam seu próprio processo de aprendizagem (ROMANOWSKI; WACHOWICZ, 2003). 
Ao organizar uma proposta formal avaliativa, é necessário que o professor selecione atividades de avaliação dentre as atividades de aprendizagem, indique os critérios pelos quais estas atividades irão ser avaliadas, retome aspectos importantes com os alunos e divulgue resultados. Todas as atividades de aprendizagem, apresentadas na proposta metodológica para o desenvolvimento das competências, devem ser analisadas e avaliadas. Entretanto, algumas são mais significativas do que outras. Estas podem compor a proposta formal de avaliação.

Nada impede que, também, ao final do processo seja estabelecida uma outra atividade de avaliação como uma prova, elaboração de um texto, práticas acompanhadas de relatórios, e outras. $\mathrm{O}$ valor atribuído a esta atividade não deve descaracterizar o processo formativo como contínuo, cumulativo, prognóstico, mas significar o coroamento do processo.

Os critérios de avaliação devem ser previamente definidos e amplamente conhecidos pelos alunos, favorecendo a transparência do processo, a orientação do trabalho discente e a co-responsabilidade do aluno no processo de aprendizagem. Segundo Wachowicz "não podemos considerá-los fixos a priori, porque se modificam ao mesmo tempo em que as ações ocorrem" (2000, p. 106). As mudanças ocorridas serão explicitadas para se tornarem conscientes e assim obterem maior participação dos alunos, inclusive na redefinição dos critérios.

Critério é um referencial que gera parâmetros pelos quais podemos observar o nível de desenvolvimento das competências por meio das atividades de avaliação realizadas. Para determiná-los podemos fazer a seguinte pergunta: o quê vai ser observado nestas atividades, para que se possa emitir um parecer sobre o quê o aluno aprendeu, aprendeu em parte ou não aprendeu?

Na divulgação dos resultados da avaliação, após correções e análise dos resultados, a devolutiva realizada de forma participativa constitui-se em um momento importante de aprendizagem. Envolve comentários sobre aspectos relevantes, reelaboração de textos e questões, repetição de demonstrações, troca de experiências e outras ações didáticas que vão sendo replanejadas, ao se defrontarem com as estratégias individuais de aprendizagem.

$\mathrm{O}$ registro do resultado final da avaliação é feito de acordo com a forma disposta nas normas da instituição.

Estas considerações reforçam que o processo de avaliação tem como objetivos: 0 desenvolvimento do aluno, a transformação da prática docente e a reelaboração contínua da ação pedagógica. É preciso revisitar sempre a concepção de educação e, por meio do processo de avaliação, tomar decisões necessárias à reconstrução do programa de aprendizagem.

Para que se construa uma ação pedagógica inovadora que caracterize o professor profissional, é importante que os procedimentos metodológi- 
cos, o processo de avaliação, as competências e os temas de estudo estejam articulados entre si, sejam vivenciados em sala e se coloquem em direção à aprendizagem significativa dos alunos.

\section{Considerações finais}

As pesquisas em metodologia e avaliação da aprendizagem no ensino superior retratam os avanços e as incertezas que permeiam a implantação de um projeto pedagógico. A rotina dominante na atividade pedagógica vigente há muito tempo fica marcada por certas representações que acabam tomando-se "concepções" que, por sua presença, constituem-se em obstáculos para qualquer mudança.

Contrapondo-se a esta situação, o primeiro passo é a reflexão sobre a própria prática pedagógica, no contexto do programa de aprendizagem realizada no coletivo dos educadores. Sendo este um momento privilegiado de mudança, cabe à instituição oportunizar situações para que a formação pedagógica dos docentes que nela atuam efetivamente se realize.

Toma-se relevante oportunizar propostas na direção do professor profissional num processo de desenvolvimento contínuo. A prática tem demonstrado que se toma necessánio atender às demandas individuais específicas, para complementação de necessidades percebidas pelos docentes.

A prática também tem demonstrado que a oferta de atividades coletivas contribui para o desenvolvimento do saber pedagógico, para análise do processo educativo e troca de experiência entre os docentes.

Esperamos que os aspectos abordados neste trabalho, mesmo tendo como foco de análise o ensino superior, possam ser válidos para outros níveis de ensino, e venham a contribuir para a discussão do processo de mudança educacional. Recomenda-se, para uma compreensão mais adequada da proposta da PUCPR, a continuidade das pesquisas em desenvolvimento, sendo este o desafio do nosso corpo docente.

\section{Referências}

ABREU, Maria Célia; MASETTO, Marcos. O Professor Universitário em aula. São Paulo, SP: MG Associados, 1990.

ANASTASIOU, Léa das Graças Camargos. Metodologia do ensino superior: da prática docente a uma possível teoria pedagógica. Curitiba: IBPEX Autores Associados, 1998.

BEHRENS, Marilda Aparecida. O paradigma emergente e a prática pedagógica. Curitiba: Champagnat, 1999. 
HADJI, Charles. Avaliação Desmistificada. Porto Alegre: Artes Médicas, 2001. MARTINS, Pura Lúcia O. A Didática na atual organização do trabalho. Uma experiência metodológica. 1985. Dissertação (Mestrado em educação). Faculdade de educação da UFMG, Belo Horizonte, 1985.

. Didática teórica, didática prática. 7. ed. São Paulo, SP: Loyola, 2002.

MASETTO, Marcos T. Atividades pedagógicas no cotidiano da sala de aula universitária: reflexões e sugestões e reflexões práticas. In: CASTANHO, S. CASTANHO, M. E. (Org). Temas e tex tos e metodologia do ensino superior. Campinas, SP: Papirus, 2001.

MEIRIEU, Philippe. Aprender, sim... mas como? Porto Alegre: Artes Médicas, 1998.

PERRENOUD, Philippe. Avaliação: entre duas lógicas. Porto Alegre: Artes Médicas, 1999.

Médicas, 1999.

. Construir as competências desde a escola. Porto Alegre: Artes . Novas competências para ensinar. Porto Alegre: Artes Médicas, 2000.

PERRENOUD, P. PAQUAY, L ALTET, M. CHARLIE E. (org.). Formando professores profissionais. Porto Alegre: Artmed, 2001.

PIMENTA, Selma Garrido. Formação de professores: saberes da docência e identidade do professor. Revista Fac. Educ, São Paulo, v.22, n. 2, 1996.

PONTIFÍCIA UNIVERSIDADE CATÓLICA DO PARANÁ. Plano Estratégico da PUCPR - Horizonte 1998 - 2010. Curitiba, 1998.

. Diretrizes para o ensino de graduação: o projeto pedagógico da Pontifícia Universidade Católica do Paraná. Curitiba: Champagnat, 2000.

ROMANOWSKI, Joana Paulin; WACHOWICZ, Ĺlian Anna. A avaliação formativa no Ensino Superior: que resistências manifestam os professores e os alunos? In: ANASTASIOU, Lea das Graças Camargos; PESSATE ALVES, Leonir. (Orgs.). Processos de ensinagem na Universidade: dos pressupostos às estratégias de trabalho em aula. Joinville: Editora da Univille, 2003.

SAVIANI, Dermeval. Os saberes implicados na formação do educador. In: SILVA JÜNIOR, Celestino Alves da. Formação do professor: dever do Estado, tarefa da universidade. São Paulo, SP: UNESP, 1996. 
TARDIF, M. RAYMOND, D. Saberes, tempo e aprendizagem do trabalho no magistério. Educação \& Sociedade, v. 21, n. 73, dez. 2000.

WACHOWICZ, Ĺlian Anna. A avaliação da aprendizagem escolar. In: CASTANHO, Sérgio. CASTANHO, Maria Eugênia LM. (Orgs.). o que há de novo na educação superior: do projeto pedagógico à prática transformadora. Campinas, SP: Papirus, 2000.

Recebido em 16/04/2003 Aprovado em 19/08/2003 